\title{
Staff Assignment to Multiple Projects Based on DEA Efficiency
}

\author{
Natasa Martinovic ${ }^{1}$, Gordana Savic ${ }^{2}$ \\ ${ }^{1}$ SAP West Balkans d.o.o. Belgrade \\ Omladinskih brigada 88b, 11070 Belgrade, Serbia \\ E-mail.natasa.martinovic@sap.com \\ ${ }^{2}$ University of Belgrade \\ Jove Ilica 154, 11000 Belgrade, Serbia \\ E-mail.gordana.savic@fon.bg.ac.rs \\ cross $^{\text {ref }}$ http://dx.doi.org/10.5755/j01.ee.30.2.20272
}

An adequate staff assignment plan is recognized as one of the most important factor for fulfilling the foreseeable delivery of multiple projects with restrictions on available budget, time and quality. This problem is very complex and becomes more complicated as the number of projects, tasks and staff members increases. Decision makers need to find a single unique performance measure as the primary criterion for making a balanced and efficient staff assignment plan. The efficiency of an assignment plan depends on different input and output criteria related to staff member performances which can be economic, qualitative or quantitative by nature. Therefore, the main question is how to make the most efficient assignment plan in multi-project, multi-task environment if several staff members can carry out different tasks at the different level of performance. This paper proposes an integration of all input-output criteria, regardless of their type through a DEA-based mixed-integer programming model. It evaluates the efficiency of staff members as a unique criterion, based on their past performances, together with making an assignment plan. Practical examples with different restrictions empirically demonstrate the possibilities of the decision model. The results show that the fulfilling of maximum efficiency criteria of all staff members in implementing the required tasks provides balanced efficiency in the implementation of all on-going projects, which makes this model a useful tool for decision makers.

Keywords: Staff Assignment Plan; Multi Project Management; Efficiency Evaluation; Data Envelopment Analysis (DEA); Mixed-integer Programming.

\section{Introduction}

In a multi-project framework, optimal allocation of the available consultants and the formation of an adequate project team for each on-going project becomes one of the most important tasks. The goal is to allocate available consultants to project and ensure the maximum value in terms of time, cost and quality (Razavi Hajiagha et al., 2015). The selection and allocation problem is complex, given that business process principal consultants (the most experienced consultants) may be engaged on several different tasks on projects and may form teams of different structure and efficiency. Therefore, it is necessary to take into consideration several different criteria related to the skills and experience of staff. On the other hand, the decision maker could have made an easier decision based on a single unique performance measure or the rank of the candidates.

This paper proposes a methodology for solving multicriteria assignment problem (Pentico, 2007) based on Data envelopment analysis (DEA) and mixed-integer programming (MIP). We determine an assignment plan which provides the highest possible overall efficiency in the implementation of all tasks on all on-going projects. Another method commonly used to solve this problem is a two-phase approach (DEA efficiency evaluation in the first phase and MIP assignment model in the second phase), as it is stated by Tavana et al., 2015. The proposed combined DEA and MIP model provides simultaneous efficiency evaluation of each consultant on each task and their assignment to the most appropriate tasks on the on-going project.

The assignment plan balances the tasks required for projects and the set of skills of business process principal consultants, such as years of experience, extent of knowledge, current reputation and other professional performance. We are considering the situation of several simultaneous projects which must be implemented in a quality manner, within specific timeframes and budgets. Each project is significant, but they still have specific priorities in implementation. Also, consultants need to be optimally deployed in a defined period on each of the agreed projects. The allocation of fixed costs and common resources depends on the achieved level of consultants' efficiency.

The paper starts with a literature review, defines the problem and specifies the characteristics essential for the efficiency evaluation process. The following sections describe the proposed DEA mixed-integer programming model and its application for optimal allocation of the available consultants to projects based on DEA efficiency, followed by a survey and its results. The conclusions and bibliography are found in the final sections. 


\section{Literature Review}

Recently, new performance evaluation systems have been proposed and presented in the scientific literature. For example, Cao \& Hoffman (2011) designed a new project performance evaluation system that would enable managers to audit a project and determine where improvements could be made. Xu \& Yeh (2014) presented a new performancebased approach for integrating project assignment and project performance evaluation, two important and separate research issues in project management, by using the expected contribution value of the projects and the expected performance score specified by project managers.

DEA is also used in different aspects of project performance evaluation. Fu \& Ou (2013) proposed a new method, combining PCA (Principal Component Analysis) and DEA to enhance the efficiency of decision-making units substantially. Sudhaman \& Thangavel (2015) identified efficient ERP projects for project managers, practitioners and consultants based on projects quality measures (defect counts) using the DEA model, thus enabling them to adopt software processes and quality models of these projects for their future ERP projects. Jahantighi et al. (2015) proposed a method for selecting high performance projects to solve a problem with limited resources for producing finite projects, in order to obtain the desired level of efficiency. Spalek (2014) determined specific roadmaps for three industries to increase project management efficiency in terms of time reduction.

Another important aspect of project management is resource allocation. Lombardi \& Milano (2012) gave a review of optimal methods for resource allocation and scheduling. Fatemi et al. (2002) considered the problem of multi-project resource allocation (MPRA) as a multi-channel queuing system and the ways to determine the optimal timing of projects in case of simultaneous multi-projects with shared resources. Van den Bergh et al. (2013) reviewed the literature, identified trends in the research on personnel scheduling problems and indicates areas which should be the subject of future research.

Wu \& An (2012) presented a new approach for resource allocation via DEA models which transforms the multiple objective linear programming (MOLP) problem into a single objective linear programming model. Hassan et al. (2010) considered a multi-objective resource allocation problem (MORAP) in which decision-making units were controlled by a central unit and use a method based on DEA model to evaluate centralized-MORAP.

There have been many approaches based on DEA method (Liu et al., 2013; Liu et al., 2016; Emrouznejad et al., 2016) which attempted to solve the problems of cost allocation and resource scheduling. Athanassopoulos (1995, 1998) used goal programming formulations integrated in the interactive planning framework to develop a DEA model for resource allocation. On the other hand, Cook \& Kress (1999) made the first attempt of fixed costs allocation, based on two theoretical principles - invariance and Pareto minimum. This approach was further expanded in a paper published 2005 (Cook \& Zhu, 2005), where the authors used the DEA approach to achieve uniform allocation of shared costs among decision making units (DMUs). Lin (2011) extended the approach given in Cook \& Zhu (2005) to obtain the permissible fixed costs or resources allocation when they were subject to special restrictions. Li et al. (2009) observed fixed costs as a complement to other inputs and combine them with other measures of costs to form a single input measure in assessing the performance.

Amirteimoori \& Tabar (2010) presented a DEA-based approach for allocating fixed resources or costs across a set of DMUs at the same time, with output targets setting allocating input resources. Keke et al. (2015) suggested the way how resources allocation mechanism of manufacturing enterprises based on multilevel programming can improve efficiency of resources allocation.

Fang (2013) introduced a new generalized centralized resource allocation and extended the Lozano \& Villa's (2004), and Asmild et al. (2009) models, which assumed that a centralized decision maker could rearrange inputs and outputs across all decision-making units. An alternative model based on the so-called centralized DEA was proposed by Lopez-Torres \& Prior (2016) in order to adapt resources to the allocated budget without losing outputs. Centralized decision making aims to minimize total amount of input or maximize the total amount of produced outputs by all decision making units, rather than considering the consumption of each individual DMU (Korhonen \& Syrjanen, 2004; Fang \& Zhang, 2008; Du et al., 2010). Wu et al. (2013) developed new DEA models based resource allocation considering both economic and environmental factors.

Du et al. (2014) used the cross-efficiency concept in DEA to approach cost and resource allocation problems. In a different manner, Hatami-Marbini et al. (2015) proposed an alternative common-weights DEA model for centrally imposed resource or output reduction across the reference set.

Obviously, DEA has become a leading approach to efficiency analysis in many fields. It is used to assess efficiency based on empirical boundaries of efficiency, but can also be used for resource allocation and setting goals for future predictions. DEA models use continual data but there are many problems in real life in which data must be treated as integer, such as the number of workers, machines, experts and other (Beasley, 2003; Lozano \& Villa, 2006; Lozano \& Villa, 2007; Kuosmanen \& Kazemi Matin, 2009; Kazemi Matin \& Kuosmanen, 2009; Wu \& Zhou, 2015; Foroughi, 2011; Gholami \& Beigi, 2013; Bernini et al., 2013; Lotfi et al., 2013).

\section{Problem Description}

As stated above, the focus of this paper is the assignment of consultants in a multi-project environment, taking into consideration several different criteria.

Most commonly, projects are contracted at the end of year, with implementation due in the following fiscal year. Consultants to be involved in the project implementation should be allocated so that all projects could be successfully implemented. Allocation plan in its entirety should be as efficient as possible.

In practice, the decision maker, has a list of consultants which can be chosen as appropriate project team members on the required tasks, taking into consideration the size of project, consultants' skills, costs, project timeline and consultants' availability in the designated period. Obviously, the decision maker often faces a multi-criteria problem and the necessity to find the best solution without 
using an exact optimization method. The problem is combinatorial and it is employed in the deployment of consultants to positions on the project based on the assessment of their performance. This is the reason for choosing efficiency as the criterion of suitability of consultants in this study.

Efficiency evaluation is based on the following criteria:

- Consultancy Cost (CC): Represents the Consultancy Services Price per person per day.

- Trainings (TR): Lists the number of courses (trainings) or certifications which a consultant has past, e.g. trainings related to the functional modules that are necessary for project implementation.

- References (RE): Defines the number of consultant references from previous projects.

- Performance \& Reward (PR): An internal process for setting objectives and assessing performance. The actual efficiency will be determined based on the consultant's performance, evaluated as employee self-assessment, manager and customer assessment and peers' assessment as additional appraisers. The PR range is 1 to 4 (1-progressing, 2-successful, 3-outstanding, 4-extraordinary). Candidates with PR equal to 1 are excluded as unsuitable.

- Customer Recommendation (CR): Score of customer satisfaction with the consultant, obtained by survey after the implementation is completed in the required areas. The scores are given on a 1 to 5 scale; however, candidates with CR less than 2.5 are excluded as unsuitable.

- Awareness of Responsibility (AR): Refers to the liability of consultants in terms of their work. The scores are based on the feedback given by team members and their experience from the previously implemented projects.

- Ability to Persuade (AP): Indicates the ability of the consultant to present best practices and convince the client to opt for a proposed solution. Communication abilities are assessed by the decision maker based on an interview with the potential candidate. Only consultants with AR and AP between 3 and 9 are taken into consideration (candidates with a score less than 3 are unsuitable).

These criteria are selected based on practical experience of ERP project implementation. Also, they are defined as the most suitable criteria for consultant selection problem in Vayvay et al. (2012).

Business processes principal consultant can be engaged as a consultant (team lead for implementation module task_1), solution architect (task_2) or project manager (task_3). However, it is not possible for the same person perform two tasks on the same project. Annual key performance indicator (KPI) defined for each staff member (which must be achieved during the year) is approximately 190 days $+20 \%$ which results in a maximum of 228 days per project team member. In this study KPIs are predefined even thought their selection can be the subject of research (Xie et all., 2017; Jahangirian et all., 2017; Fuentes et all., 2016; Collins et all., 2016). Tao (2012) proposed a methodology for the selection of KPIs, their aggregation into four dimensions of Workforce Scorecard (WS) and the employees' performance evaluation using DEA.

Martinovic \& Delibasic (2013) used Analytic Hierarchy Process (AHP) method combined with Interpolative realization of Boolean algebra to generate new criteria that include the relationship between the initial criteria. They adopted the model given in Vayvay et al. (2012), where AHP, Fuzzy AHP and Analytic Network Process (ANP) are used, for the specific case of selecting the most suitable consultant to be engaged in ERP implementation. For efficiency evaluations on a small sample with a number of criteria, another model was applied in research of Martinovic \& Savic (2015). They modified DEA model by reducing the number of criteria with implying 'Exclusive OR' rules.

\section{Research Methodology}

The problem of interest is to allocate consultants in a multi-project, multi-task environment. Assumptions of the decision problem are as follows:

- At the beginning of the fiscal year, a set of $P$ projects are to be started and implemented until the end of observed period.

- Each project $p \in P$ involves set of $L$ tasks.

- A set of consultants $C$ is given (known) and each consultant can perform one or more tasks $l \in L$.

- A consultant $c \in C$ would perform an assigned task $l(l \in L)$ at the same level as it was in the past. Historical data on consultants' KPIs are known.

- The efficiency of one project is calculated as the addition of efficiencies of all assign consultants.

Staff allocation means selecting and assigning consultant $c(c \in C)$ to perform task $l(l \in L)$ on project $p(p \in P)$. The goal is to realize all projects in the most efficient way. The decision is based on historical data of consultants' KPIs, and time resources requirements for all projects $p \in P$.

The problem belongs to a group of complex, combinatorial problems. The maximal number of possible combinations for full coverage of all tasks on all projects by all consultants is $|P| \times|L| \times|C|$. In order to easily solve the defined problem, the approximate approach is employed. Having the assumptions given above, the possible set of covering (Crhistofides \& Korman, 1975) schemes $S$ is made in advanced. One scheme $s \in S$ corresponds to the combination project-task-consultant and represents a triplet $(p, l, c),(p \in P, l \in L, c \in C)$. Therefore, the number of feasible schemes $|S|$ is less than or equal to the number of combinations in case of full coverage $(|P| \times|L| \times|C|)$, and depends on the capability of consultants to perform tasks required by the on-going projects.

The aim is to select the subset of schemes $S$ so that all projects are performed with maximal relative efficiency. This means that relative efficiency of project $p \in P$ is equal to the sum of efficiencies of all selected corresponding schemes $S p(S p \subset S, p \in P)$. On the top level, the overall relative efficiency would be the sum of efficiencies of all selected schemes for all projects.

A mixed-integer (binary) program, as a modification of DEA prioritization model (Cook \& Green, 2000) is proposed for modelling the efficiency assessment and staff 
assignment simultaneously. The schemes are considered as $\mathrm{DMU}_{s}(s \in S)$ and characterized with a set of inputs $I$ and outputs $O$. The values of inputs $x_{i s}(i \in I, s \in S)$ and outputs $y_{r s}(r \in O, s \in S)$ are given as historical data of KPIs for the corresponding consultant $(c \in C)$ performing a task $(l \in L)$.

Preliminary, DEA-based model (Charnes et al., 1978) can be used to evaluate the efficiency $e_{s}$ of each scheme $(s \in S)$ by choosing input weights $u_{i}(i \in I)$ and output weights $v_{r}(r \in O)$ with a restriction that efficiency score should be less than or equal to 1 .

As an extension, a DEA prioritization model (Cook \& Green, 2000) provides a selection of project portfolio and additionally imposes a binary variable to indicate if a project is selected or not. In this paper, we impose binary variable $q_{s}$ to indicate if scheme $s(s \in S)$ is selected or not. If $q_{s}=1$, schemes $s$ is selected - corresponding consultant $c \in C$ is allocated to perform task $l \in L$ on project $p \in P$ . Additionally, time consumption for each task $l \in L$ on the project $p \in P$, means that time consumption $t_{s}(s \in S)$ is given in advance and imposed as restriction into the model. The assigned consultant is obligated to finalize the task on time and fulfil the required number of working days on the project, but s/he can organize working day dynamics on their own. The maximum number of working days $T$ allowed for each consultant in the observed period is also given in advance. The required number of consultants $U_{l p}$ on the concrete task $l \in L$ on the project $p \in P$ is also imposed as a constraint. This paper proposes a modified DEA-based mixed-integer programming model (1-7) for schemes selection, i.e. choosing a concrete consultant to perform a concrete task on a concrete project.

$$
\begin{aligned}
& \max e=\sum_{s \in S} e_{s}=\sum_{s \in S} q_{s}\left(\sum_{r \in O} v_{r} y_{r s}\right) \\
& \text { s.t } \\
& \sum_{s \in S p \subset S} q_{s}\left(\sum_{i \in I} u_{i} x_{i s}\right)=1, \forall p \in P \\
& \sum_{r \in O} v_{r} y_{r s}-\sum_{i \in I} u_{i} x_{i s} \leq 0, \quad s \in S \\
& \sum_{s \in S_{l p} \subset S} q_{s}=U_{l p}, \forall l \in L, \forall p \in P \\
& \sum_{s \in S_{c} \subset S} q_{s} t_{s} \leq T, \forall c \in C \\
& q_{s} \in\{0,1\}, s \in S \\
& v_{r} \geq 0, u_{i} \geq 0, r \in O, i \in I
\end{aligned}
$$

The objective function (eq. 1) maximizes the overall efficiency of all selected schemes. The upper limit of overall efficiency per each project $\forall p \in P$ is set to 1 by constraint (eq. 2). This constraint summarises virtual input of schemes in subset $S p \subset S$ which correspond to concrete project $p \in P$. Eq. (3) limits other schemes to be evaluated with rate less than or equal to 1 . The required number of consultants $U_{l p}$ is emulated as a sum of schemes selected from the corresponding subset $S_{l p} \subset S,(l \in L, p \in P)$ by eq. (4). The limitation on the maximum number of working days given in the eq. (5) is calculated as sum of time consumption $t_{s}$ for the selected schemes from subset of schemes $S_{c}$ related to consultant $c$.

The proposed model (1-7) is non-linear. Even though, the software capable of solving it is available, it might be time consuming. In order to overcome this problem, the model can be linearized by imposing new variables $g_{i s}=q_{s} u_{i}$ and $f_{r s}=q_{s} v_{r}$, and new constraints (13-18) to connect those new variables with the original ones $u_{i}, v_{r}$ and $q_{s}$. Now, DEA-based mixed-integer linear programming model is given by eqs. (8-19):

$$
\max e=\sum_{s \in S} \sum_{r \in O} f_{r s} y_{r s}
$$

$$
\text { s.t }
$$$$
\sum_{s \in S p \subset S} \sum_{i \in I} g_{i s} x_{i s}=1, p \in P
$$

$\sum_{r \in O} v_{r} y_{r s}-\sum_{i \in I} u_{i} x_{i s} \leq 0, \quad s \in S$

$\sum_{s \in S_{l p} \subset S} q_{s}=U_{l p}, \forall l \in L, \forall p \in P$

$\sum_{s \in S_{c} \subset S} q_{s} t_{s} \leq T, \forall c \in C$

$f_{r s} \leq q_{s} M, r \in R, s \in S$

$v_{r}-\left(1-q_{s}\right) M \leq f_{r s} \leq v_{r}, r \in R, s \in S$

$g_{i s} \leq q_{s} M, i \in I, s \in S$

$u_{i}-\left(1-q_{s}\right) M \leq g_{i s} \leq u_{i}, i \in I, s \in S$

$q_{s} \in\{0,1\}, s \in S$

$f_{r s} \geq 0, g_{\text {is }} \geq 0, r \in O, i \in I, s \in S$

$v_{r} \geq 0, u_{i} \geq 0, r \in O, i \in I$

where $M$ represents a big positive multiplier. The model solution denotes the overall efficiency of all selected schemes in the term of weights of input $\left(u_{i} \geq 0, i \in I\right)$, weights of outputs $\left(v_{r} \geq 0, r \in O\right)$, selection variable $q_{s} \in\{0,1\}, s \in S$ and composite multipliers $f_{r s}$ and $g_{i s}$. Consequently, triplet project-task-consultant $(p, l, c)$ selection is provided together with its efficiency evaluation.

\section{Results and Discussion}

\section{Case Study Background}

The real-world problem considered in this paper assumes the implementation of three IT projects (P1-P3) simultaneously. These projects are only limited by size (one big, one medium and one small size), but not by the scope and the type of tasks to be performed. Successful implementation of each project assumes engaging two project consultants (T1), one solution architect (T2) and one 
project manager (T3), which means four consultants in total on each project. On the other hand, there are eight candidates capable of performing the required task as given in the graph (Figure 1). The maximal possible number of schemes projecttasks-consultants is $|P| \times|L| \times|C|=3 \times 3 \times 8=72$. But feasible set $S$ consists of 45 schemes (15 for each project) which are defined in accordance with projects, tasks and consultants capable to perform them, as given in Figure 1. Each consultant can perform task T1, but only 3 consultants (C3, C6 and C7) can perform task T2 and only four of them (C3, C6, C7 and C8) are capable of fulfil task T3 successfully. Finally, the data set consists of 45 schemes (DMUs). Efficiency evaluation is based on seven KPIs defined in section 3. This KPI set is divided into sets of inputs and outputs, according to the characteristics, the cost of the consultant and her/his results. In addition to the consultancy cost (CC) criterion, the following criteria performance \& reward (PR), number of references (RE) and completed trainings (TR) as measures of experience and education of the consultant - are taken as inputs. The criterion of customer recommendation $(\mathrm{CR})$ and two criteria of communication ability (AR and AP) are taken as outputs. The criteria values for consultants are given based on the author's experience in project implementations, interviews with other senior delivery managers and experience of implementation in companies in the past. The given values are a simulation of the real market values, due to data confidentiality. Initial values for inputs and outputs, in accordance with the assessment of the decision maker, are given in Table 2 .

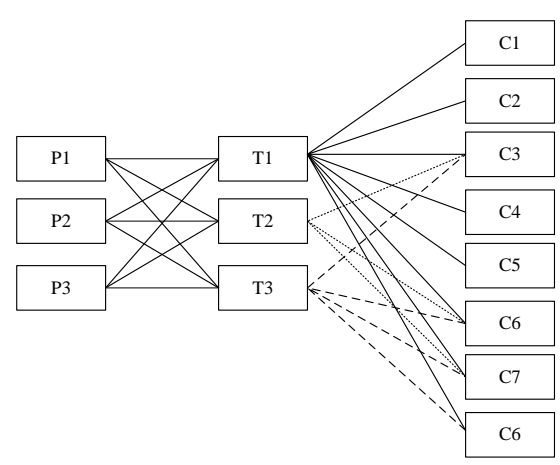

Figure 1. Project-Task-Consultant Relationships

The model (8-19) is extended with the constraint that one consultant can perform only one task on one project (eq. 20).

$$
\sum_{s \in S_{l c} \subset S} q_{s} \leq 1, l=1, c \in C
$$

where $S_{l c} \subset S$ represents the corresponding subset of schemes $(l \in L, p \in P)$.

Data on Required Days

\begin{tabular}{|c|c|c|c|c|}
\hline Project & Task & Required days per task & Required number of consultants per task & Total \\
\hline $\mathrm{P} 1$ & $\mathrm{~T} 1$ & 144 & 1 & \\
\hline $\mathrm{P} 1$ & $\mathrm{~T} 2$ & 72 & 1 & 504 \\
\hline $\mathrm{P} 1$ & $\mathrm{~T} 3$ & 144 & 2 & \\
\hline $\mathrm{P} 2$ & $\mathrm{~T} 1$ & 120 & 1 & \\
\hline $\mathrm{P} 2$ & $\mathrm{~T} 2$ & 60 & 1 & 420 \\
\hline $\mathrm{P} 2$ & $\mathrm{~T} 3$ & 120 & 2 & \\
\hline P3 & $\mathrm{T} 1$ & 96 & 1 & \\
\hline P3 & $\mathrm{T} 2$ & 48 & 1 & 336 \\
\hline P3 & $\mathrm{T} 3$ & 96 & 2 & \\
\hline
\end{tabular}

In addition, maximum time limit for each consultant is defined at level of 228 days annually (1824 days in total) and the required time for performing each task on each project is also given in advance (Table 1). The total time needed for performing all tasks is 1260 days. This way, a feasible solution is provided: it is expected that an optimal assignment plan can be found since there are more available work days than required.

\section{Results}

Efficiency scores for all schemes are calculated using model (8-20) and are shown in Table 2. According to the model, the efficiency scores of schemes depend on the input and output values with the constraint that the virtual input of any project must be equal to 1 . The expected efficiency index value for each DMU (scheme) is 0.25 . Accordingly, efficiency scores differ for each combination of task-consultant, regardless of the project being implemented. The most efficient consultants, with the score of 0.2938 , are C3 in performing any task (T1, T2 or T3) and C6 in performing task T1.

Binary variables $q_{s}, s \in S$, which indicate if scheme $s$ is selected or not, are given in the Table 3 . A detailed analysis of the assignment plan shows that the assignment of consultants is fair, taking into consideration the overall efficiency of the projects. Consultants implementing projects $\mathrm{P} 2$ and P3 are expected to be the most efficient, but with a small difference of 0.0167 in comparison to project P1. All projects are implemented with an efficiency score over 0.93 . 
Table 2

Input and Output Values and Efficiency Score

\begin{tabular}{|c|c|c|c|c|c|c|c|c|c|}
\hline \multirow{3}{*}{ Task $L$} & \multirow{3}{*}{ Consultant $C$} & \multicolumn{4}{|c|}{ Inputs } & \multicolumn{3}{|c|}{ Outputs } & \multirow{3}{*}{ Efficiency scores } \\
\hline & & $\mathrm{CC}$ & TR & $\mathrm{RE}$ & PR & $\mathrm{CR}$ & AR & AP & \\
\hline & & $x_{1 s}$ & $x_{2 s}$ & $x_{3 s}$ & $x_{4 s}$ & $y_{1 s}$ & $y_{2 s}$ & $y_{3 s}$ & \\
\hline $\mathrm{T} 1$ & $\mathrm{C} 1$ & 400 & 2 & 4 & 2 & 3 & 5 & 3 & 0.1734 \\
\hline $\mathrm{T} 1$ & $\mathrm{C} 2$ & 450 & 3 & 5 & 2 & 3.25 & 5 & 7 & 0.1849 \\
\hline $\mathrm{T} 1$ & $\mathrm{C} 3$ & 500 & 5 & 6 & 4 & 5 & 9 & 9 & 0.2938 \\
\hline $\mathrm{T} 2$ & $\mathrm{C} 3$ & 500 & 4 & 3 & 4 & 5 & 9 & 9 & 0.2938 \\
\hline $\mathrm{T} 3$ & $\mathrm{C} 3$ & 500 & 3 & 3 & 4 & 5 & 9 & 9 & 0.2938 \\
\hline $\mathrm{T} 1$ & $\mathrm{C} 4$ & 470 & 3 & 2 & 2 & 3.5 & 5 & 5 & 0.1963 \\
\hline $\mathrm{T} 1$ & $\mathrm{C} 5$ & 490 & 3 & 4 & 3 & 4.3 & 7 & 7 & 0.2474 \\
\hline $\mathrm{T} 1$ & C6 & 550 & 5 & 7 & 4 & 5 & 9 & 9 & 0.2938 \\
\hline $\mathrm{T} 2$ & C6 & 550 & 4 & 4 & 3 & 4.8 & 9 & 9 & 0.2847 \\
\hline $\mathrm{T} 3$ & C6 & 550 & 3 & 2 & 2 & 4.5 & 7 & 7 & 0.2565 \\
\hline $\mathrm{T} 1$ & $\mathrm{C} 7$ & 520 & 4 & 2 & 2 & 3.65 & 5 & 3 & 0.2032 \\
\hline $\mathrm{T} 2$ & C7 & 520 & 3 & 2 & 2 & 2.9 & 3 & 4 & 0.1545 \\
\hline $\mathrm{T} 3$ & $\mathrm{C} 7$ & 520 & 1 & 1 & 2 & 2.6 & 5 & 2 & 0.1551 \\
\hline $\mathrm{T} 1$ & $\mathrm{C} 8$ & 510 & 5 & 4 & 3 & 5 & 6 & 6 & 0.2723 \\
\hline $\mathrm{T} 3$ & $\mathrm{C} 8$ & 510 & 2 & 2 & 2 & 4 & 7 & 5 & 0.2336 \\
\hline
\end{tabular}

Only four consultants (C3, C6, C7 and C8) can perform tasks T2 and T3. The main problem is how to deploy them to 6 positions (T2 and T3 on $\mathrm{P} 1, \mathrm{P} 2$ and $\mathrm{P} 3$ ) without overloading the limited number of annual working days. This problem is solved by excluding consultant $\mathrm{C} 7$ as a candidate for these tasks because s/he has the lowest relative efficiency (0.15-0.20) caused by the lowest levels of output performance (CR, AR and AP) and high labour costs (CC). The consultant $\mathrm{C} 3$ will act as a solution architect on all ongoing projects, and the consultant $\mathrm{C} 8$ will be employed as project manager on two projects (P2 and P3). Consultant C6 is assigned as project manager on project $\mathrm{P} 1$. The T3 tasks on all projects are assigned to the available consultants $\mathrm{C} 1$, $\mathrm{C} 2, \mathrm{C} 4$ and $\mathrm{C} 5$ considering the remaining working days and efficiency scores. The most burdened consultants in terms of time are $\mathrm{C} 1, \mathrm{C} 5$ and $\mathrm{C} 8$ while consultant $\mathrm{C} 7$ is not employed at all, since s/he has the lowest efficiency score (last column in Table 3).

Another possible extension of the model could be achieved by imposing constraint to the maximal number of projects $(N)$ where a consultant can be assigned to the same task (eq. 21).

$$
\sum_{s \in S_{l c} \subset S} q_{s} \leq N, l \in L, c \in C
$$

Model (8-21) is solved in the two following practical cases:

1. business processes principal consultant can be assigned as project manager to only one project $(21-1)$;

2. business processes principal consultant can be assigned as project manager to only one project and as a solution architect to only one project (212).

Additional restrictions caused decrease in the overall efficiency of project implementation in comparison to the efficiency presented in Table 3, but the rank of taskconsultants is the same. In this case, the most inefficient consultant C7 cannot be excluded. S/he takes task T1 (consultant) on project $\mathrm{P} 2$ and task $\mathrm{T} 2$ (solution architect) on project $\mathrm{P} 3$, which causes a decrease in overall efficiency score (0.9426/0.9329/0.9092). The consultant's time burden also varies in comparison to the assignment shown in Table 3. The most burdened candidates are $\mathrm{C} 6, \mathrm{C} 8$ and $\mathrm{C} 3$.

Table 3

Consultant Assignment

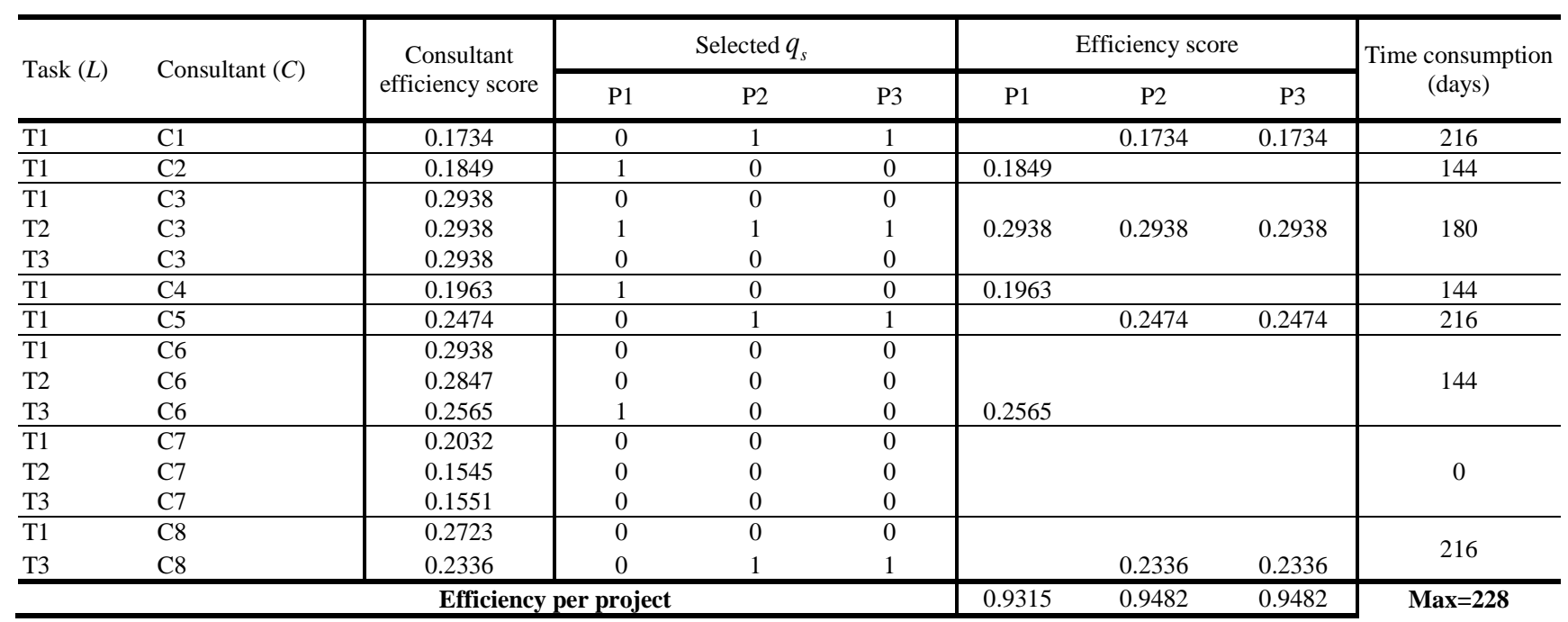




\section{Discussions}

The success of the project implementation greatly depends on allocated resources. Therefore, resource mobilization is one of the inputs frequently used for project performance evaluation (Iyer et al., 2016). Problems of project portfolio selection (Cook \& Green, 2000; Tavana et al., 2015; Perez \& Gomez, 2016) and project manager selection (Hadad et al., 2013) are also frequently considered in the literature. A general problem of staff selection and assignment (Wu \& Sun, 2006; Bassett, 2000) is more complicated in multi-criteria, multi-project, multi-task framework. The practical significance of solving this problem is evident since a company usually signs contracts for the simultaneous implementation of several same or similar projects. This is very common in the implementation of IT projects.

In this paper, staff selection and assignment is done based on DEA efficiency, which may be considered as a contribution of this paper. The first step in consultant assignment is to select key performance indicators (KPIs) to be used as inputs and outputs. This selection is very important since it has a crucial impact on efficiency evaluation. This paper proposes seven KPIs significant for IT project implementation together with annual working days. The second step is a priori defining a set of all schemes covering triples of project, task and consultants. The third step is to choose a proper optimization model. The proposed model (8-19) can be used as a basic model for staff assignment in different areas by introducing different KPIs. The advantage of this approach is that this model can easily be extended by imposing constraints significant for practical implementation (eqs. 20 and 21).

The existence of a feasible solution will be provided if the total number of working days for all available consultants is greater than or equal to the required number, and if there is a sufficient number of candidates capable of performing individual tasks on all projects. The solution of the proposed model can improve the process of decision making by simultaneous efficiency evaluation, staff selection and assignment.

The proposed model does not cover time dynamic and does not include projects that should start latter than beginning of the fiscal year. Time dimension can be included by introducing the available working days for each consultant as a difference between maximal and assigned days (Bassett, 2000; Greiner \& Ennsfellner, 2010). Another potential limitation of proposed approach appears when solving a large dimension problem, since schemes definition and solving the problem with many binary variables can be time-consuming. This issue opens an area for further research and the development of constructive heuristics (Sapkota \& Reilly, 2011).

\section{Conclusions and Further Research}

This paper proposes a methodology which aims to solve the problem of simultaneous consultant assignment and efficiency evaluation in multi-criteria, multi-project, multi-task framework. Usually, in the real world, the decision maker understands that the main cause of problems in the selection and assignment of consultants is the inability to choose the best consultants when there are several alternatives. The second cause lies in the selection of the most appropriate and measurable criteria from the list. The decision maker could have made an easier decision based on a unique performance measure or rank of candidates. This means that criteria should be aggregated into one measure such as efficiency.

The methodology for staff (consultant) assignment based on efficiency evaluation includes multiply input and output criteria is set out in this paper. Historical data on selected staff performance and working days' requirements are used as criteria. The proposed DEA-based mixed-integer programming model enables efficiency evaluation of each consultant in fulfilling any task within the peer-group of consultants based on past performances and cost. Therefore, their ranking and benchmarking is provided. Another important feature is that the model provides the most efficient assignment plan, together with the expected efficiency in the implementation of each individual project within the overall efficiency.

The results of the real-world case study with three projects have shown the applicability and usability of the proposed model. The ease of adaptation and modification of the model for the practical application is also one of the benefits of the presented approach.

The approach proposed in this paper can be generally applied to making an adequate staff assignment plan, especially in application and projects implementation in IT sector. In practice, to apply the proposed model, decision maker need to select efficiency evaluation criteria, group them into inputs and outputs, define project-taskconsultant relationships.

Further research can be directed towards modifying model by included priorities for projects and/or tasks implementation and the partial allocation of human resources in terms of time. Another direction can be developing the heuristics for easier and faster-finding solutions for large-dimension problems.

\section{References}

Amirteimoori, A., \& Tabar, M. M. (2010). Resource Allocation and target setting in Data Envelopment Analysis. Expert System with Application, 37(4), 3036-3039. https://doi.org/10.1016/j.eswa.2009.09.029.

Asmild, M., Paradi, J. C., \& Pastor, J. T. (2009). Centralized resource allocation BCC models. Omega International Journal of Management Science, 37(1), 40-49. https://doi.org/10.1016/j.omega.2006.07.006.

Athanassopoulos, A. D. (1998). Decision support for target-based resource allocation of public service in multiunit and multilevel systems. Management Science, 44(2), 173-187. https://doi.org/10.1287/mnsc.44.2.173 
Athanassopoulos, A.D. (1995). Goal programming and data envelopment analysis (GoDEA) for target-based multi-level planning: Allocating central grants to the Greek local authorities. European Journal of Operational Research, 87(3), 535-550. https://doi.org/10.1016/0377-2217(95)00228-6.

Bassett, M. (2000). Assigning projects to optimize the utilization of employees'time and expertise. Computers \& Chemical Engineering, 24(2/7), 1013-1021. https://doi.org/10.1016/S0098-1354(00)00534-2.

Beasley, J. (2003). Allocating fixed costs and resources via data envelopment analysis. European Journal of Operational Research, 147(1), 198-216. https://doi.org/10.1016/S0377-2217(02)00244-8.

Bernini, C., Guizzardi, A., \& Angelini, G. (2013). DEA-like model and common weights approach for the construction of a subjective community well-being indicator. Social indicators research, 114(2), 405-424. https://doi.org/10.10 07/s11205-012-0152-3.

Cao, Q., \& Hoffman, J. J. (2011). A case study approach for developing a project performance evaluation system. International Journal of Project Management, 29(2), 155-164. https://doi.org/10.1016/j.ijproman.2010.02.010.

Charnes, A., Cooper, W. W., \& Rhodes, E. (1978). Measuring the efficiency of Decision Makin Units. European Journal of Operational Research, 2(6), 429-444. https://doi.org/10.1016/0377-2217(78)90138-8.

Collins, A. J., Hester, P., Ezell, B., \& Horst, J. (2016). An improvement selection methodology for key performance indicators. Environment Systems \& Decisions, 36(2), 196-208. https://doi.org/10.1007/s10669-016-9591-8.

Cook, W. D., \& Zhu, J. (2005). Allocation of shared costs among decision making units: A DEA approach. Computers \& Operations Research, 32(8), 2171-2178. https://doi.org/10.1016/j.cor.2004.02.007.

Cook, W. D., \& Green, R. H. (2000). Project prioritization: a resource-constrained data envelopment analysis approach. Socio-Economic Planning Sciences, 34(2), 85-99. https://doi.org/10.1016/S0038-0121(99)00020-8.

Cook, W. D., \& Kress, M. (1999). Characterizing an equitable allocation of shared costs: A DEA approach. European Journal of Operational Research, 119(3), 652-661. https://doi.org/10.1016/S0377-2217(98)00337-3.

Crhistofides, N., \& Korman, S. (1975). A computational survey of methods for the set covering problem. Management Science, 21, 591-599. https://doi.org/10.1287/mnsc.21.5.591.

Du, J., Cook, W. D., Liang, L., \& Zhu, J. (2014). Fixed cost and resource allocation based on DEA cross-efficiency. European Journal of Operational Research, 235(1), 206-214. https://doi.org/10.1016/j.ejor.2013.10.002.

Du, J., Liang, L., Chen, Y., \& Bi, G. (2010). DEA-based production planning. Omega International Journal of Management Science, 38(1-2), 105-112. https://doi.org/10.1016/j.omega.2009.07.001.

Emrouznejad, A., Banker, R., Ahn, H., \& Afsharian, M. (2016, February). Data Envelopment Analysis and its Applications. Proceedings of the 13th International Conference of DEA, August 2015, Braunschweig, Germany.

Fang, L. (2013). A generalized DEA model for centralized resource allocation. European Journal of Operational Research, 228(2), 405-412. https://doi.org/10.1016/j.ejor.2013.01.049.

Fang, L., \& Zhang, C. Q. (2008). Resource allocation based on the DEA model. Journal of the Operational Research Society, 59(8), 1136-1141. https://doi.org/10.1057/palgrave.jors.2602435.

Fatemi Ghomi, S. M. T., \& Ashjari, B. (2002). A simulation model for multi-project resource allocation. International Journal of Project Management, 20(2), 127-130. https://doi.org/10.1016/S0263-7863(00)00038-7.

Foroughi, A. A. (2011). A new mixed integer linear model for selecting the best decision making units in data envelopment analysis. Computers and Industrial Engineering, 60(4), 550-554. https://doi.org/10.1016/j.cie.2010.12.012.

Fu, H. P., \& Ou, J. R. (2013). Combining PCA with DEA to improve the evaluation of project performance data: a Taiwanese Bureau of Energy case study. Project Management Journal, 44(1), 94-106. https://doi.org/10.10 02/pmj. 21323

Fuentes, R., Fuster, B., \& Lillo-Banuls, A. (2016). A three-stage DEA model to evaluate learning-teaching technical efficiency: Key performance indicators and contextual variables. Expert Systems with Applications, 48, 89-99. https://doi.org/10.1016/j.eswa.2015.11.022.

Gholami, K., \& Beigi, Z. G. (2013). Allocating the Fixed Resources and Setting Targets in Integer Data Envelopment Analysis. Journal of Data Envelopment Analysis and Decision Science, 2013, 1-12. https://doi.org/10.5899/2013/dea00030

Greiner, L., \& Ennsfellner, I. (2010). Management consultants as professionals, or are they? Organizational Dynamics, 39(1),72-83. https://doi.org/10.1016/j.orgdyn.2009.10.003.

Hadad, Y., Keren, B., \& Laslo Z. (2013).A decision-making support system module for project manager according to past performance. International Journal of Project Management, 31(4), 532-541. https://doi.org/10.1016/j.ijpro man.2012.10.004. 
Hassan, N., Tabar, M. M., \& Shabanzade, P. (2010). A ranking model of data envelopment analysis as a centralized multi objective resource allocation problem tool. Australian Journal of Basic and Applied Sciences (AJBAS), 4(10), 53065313.

Hatami-Marbini, A., Tavana, M., Agrell, P. J., Lotfi, F. H., \& Beigi, Z. G. (2015). A common-weights DEA model for centralized resource reduction and target setting. Computers Industrial Engineering, 79, 195-203. https://doi.org/10.1 016/j.cie.2014.10.024.

Iyer, K. C., \& Banerjee, P. S. (2016). Measuring and benchmarking managerial efficiency of project execution schedule performance. International Journal of Project Management, 34(2), 219-236. https://doi.org/10.1016/j.ijpro man.2015.10.008.

Jahangirian, M., Taylor, S. J., Young, T., \& Robinson, S. (2017). Key performance indicators for successful simulation projects. Journal of the Operational Research Society, 68(7), 747-765. https://doi.org/10.1057/JORS.2016.1.

Jahantighi, M., Moghaddas, Z., \& Vaez Ghasemi, M. (2015). Project selection with limited resources in data envelopment analysis. International Journal of Industrial Mathematics, 7(1), 71-76.

Kazemi Matin, R., \& Kuosmanen, T. (2009). Theory of integer-valued data envelopment analysis under alternative returns to scale axioms. Omega International Journal of Management Science, 37(5), 988-995. https://doi.org/10.1016/j.ome ga.2008.11.002.

Keke B., Wei P., Nan Z., \& Jiang, B. (2015). Research on Resources Allocation Mechanism of Manufacturing Enterprises Base on Multi-Level Programming. Conference: 2015 International Conference on Mechatronics, Electronic, Industrial and Control Engineering (MEIC2015), April 1-3, 2015, Shenyang, China. https://doi.org/10.2991/meic15.2015.166.

Korhonen, P., \& Syrjanen, M. (2004). Resource allocation based on efficiency analysis. Management Science, 50(8), 11341144. https://doi.org/10.1287/mnsc.1040.0244.

Kuosmanen, T., \& Kazemi Matin, R. (2009). Theory of integer-valued data envelopment analysis. European Journal of Operational Research, 192(2), 658-667. https://doi.org/10.1016/j.ejor.2007.09.040.

Li, Y., Yang, F., Liang, L., \& Hua, Z. (2009). Allocating the fixed cost as a complement of other cost inputs: A DEA approach. European Journal of Operational Research, 197(1), 389-401. https://doi.org/10.1016/j.ejor.2008.06.017.

Lin, R. (2011). Allocating fixed cost or resources and setting targets via data envelopment analysis. Applied Mathematics and Computation, 217(13), 6349-6358. https://doi.org/10.1016/j.amc.2011.01.008.

Liu, J.S., Lu, L. Y. Y., \& Lu, W. M. (2016). Research fronts in data envelopment analysis. Omega International Journal of Management Science, 58, 33-45. https://doi.org/10.1016/j.omega.2015.04.004.

Liu, J. S., Lu, L. Y. Y., Lu, W. M., \& Lin, B. J. Y. (2013). A survey of DEA applications. Omega International Journal of Management Science, 41(5),893-902. https://doi.org/10.1016/j.omega.2012.11.004.

Lombardi, M., \& Milano, M. (2012). Optimal methods for resource allocation and scheduling: a cross-disciplinary survey. Constraints, 17(1), 51-85. https://doi.org/10.1007/s10601-011-9115-6.

Lopez-Torres, L., \& Prior, D. (2016). Centralized allocation of human resources. An application to public schools. Computers \& Operations Research, 73, 104-114. https://doi.org/10.1016/j.cor.2016.04.001.

Lotfi, F. H., Hatami-Marbini, A., Agrell, P. J., Aghayi, N., \& Gholami, K. (2013). Allocating fixed resources and setting targets using a common-weights DEA approach. Computers and Industrial Engineering, 64(2), 631-640. https://doi.org/10.1016/j.cie.2012.12.006.

Lozano, S., \& Villa, G. (2007). Integer DEA Models. In: Zhu J., Cook W.D. (eds) Modelling Data Irregularities and Structural Complexities in Data Envelopment Analysis. Springer, Boston, MA, 271-289. https://doi.org/10.1007/9780-387-71607-7_15.

Lozano, S., \& Villa, G. (2006). Data envelopment analysis of integer-valued inputs and outputs. Computers \& Operations Research, 33(10), 3004-3014. https://doi.org/10.1016/j.cor.2005.02.031.

Lozano, S., \& Villa, G. (2004). Centralized Resource Allocation Using Data Envelopment Analysis. Journal of Productivity Analysis, 22(1-2), 143-161. https://doi.org/10.1023/B:PROD.0000034748.22820.33.

Martinovic, N., \& Savic, G. (2015). Selection of the project consultants based on DEA efficiency. 34th International Conference on Organizational Science Development. Faculty of Organizational Sciences, University of Maribor, Portoroz, Slovenia, Internationalization and Cooperation (ISBN 978-961-232-283-0), 148-160.

Martinovic, N., \& Delibasic, B. (2013). Selection of the best consultant for SAP ERP project using combined AHP-IBA approach.Yugoslav Journal of Operations Research, 24(3), 383-398. https://doi.org/10.2298/YJOR140228036M

Pentico, D. W. (2007). Assignment problems: A golden anniversary survey. European Journal of Operational Research, 176(2), 774-793. https://doi.org/10.1016/j.ejor.2005.09.014 
Perez, F., \& Gomez, T. (2016). Multiobjective project portfolio selection with fuzzy constraints. Annals of Operations Research, 245(1/2), 7-29. https://doi.org/10.1007/s10479-014-1556-z.

Razavi Hajiagha, S. H., Akrami, H., Hashemi, S. S., \& Mahdiraji, A. H. (2015). An Integer Grey Goal Programming for Project Time, Cost and Quality Trade-Off. Inzinerine Ekonomika-Engineering Economics, 26(1), 93-100. https://doi.org/10.5755/j01.ee.26.1.9930.

Sapkota, N., \& Reilly, C. H. (2011). Simulating realistic set covering problems with known optimal solutions. Computers \& Industrial Engineering, 61(1), 39-47. https://doi.org/10.1016/j.cie.2011.02.008.

Spalek, S. (2014). Finding a New Way to Increase Project Management Efficiency in Terms of Time Reduction. Inzinerine Ekonomika-Engineering Economics, 25(5), 538-548. http://dx.doi.org/10.5755/j01.ee.25.5.8419.

Sudhaman, P., \& Thangavel, C. (2015). Efficiency analysis of ERP projects-software quality perspective. International Journal of Project Management, 33(4), 961-970. https://doi.org/10.1016/j.ijproman.2014.10.011.

Tao, G. (2012). Multi-Department Employee Performance Evaluation Based on DEA Cross Efficiency. Journal of Emerging Trends in Economics and Management Sciences (JETEMS), 3(5), 553-558.

Tavana, M., Keramatpour, M., Santos-Arteaga, F. J., \& Ghorbaniane, E. (2015). A fuzzy hybrid project portfolio selection method using data envelopment analysis, TOPSIS and integer programming. Expert Systems with Applications, 42(22), 8432-8444. https://doi.org/10.1016/j.eswa.2015.06.057.

Van den Bergh, J., Belien, J., De Bruecker, P., Demeulemeester, E., \& De Boeck, L. (2013). Personnel scheduling: A literature review. European Journal of Operational Research, 226(3), 367-385. https://doi.org/10.1016 /j.ejor.2012.11.029.

Vayvay, O., Ozcan, Y., \& Cruz-Cunha, M. (2012). ERP consultant selection problem using AHP, fuzzy AHP and ANP - a case study in Turkey. E3 Journal of Business Management and Economics, 3 (3), 106-117.

Wu, J., \& Zhou, Z. (2015). A mixed-objective integer DEA model. Annals of Operations Research, 228(1), 81-95. https://doi.org/10.1007/s10479-011-0938-8.

Wu, J., An, Q., Ali, S., \& Liang, L. (2013). DEA based resource allocation considering environmental factors. Mathematical and Computer Modelling, 58(5-6), 1128-1137. https://doi.org/10.1016/j.mcm.2011.11.030.

Wu, J., \& An, Q. (2012). New approaches for resource allocation via DEA models. International Journal of Information Technology Decision Making, 11(1), 103-117. https://doi.org/10.1142/S0219622012500058.

Wu, M.C., \& Sun, S.H. (2006). A project scheduling and staff assignment model considering learning effect. The International Journal of Advanced Manufacturing Technology, 28(11/12), 1190-1195. https://doi.org/10.1007/ s00170-004-2465-0.

Xie, L. L., Xia, B., Hu, Y., Shan, M., Le, Y., \& Chan, A. P. (2017). Public participation performance in public construction projects of South China: A case study of the Guangzhou Games venues construction. International Journal of Project Management, 35(7), 1391-1401. https://doi.org/10.1016/j.ijproman.2017.04.003.

$\mathrm{Xu}$, Y., \& Yeh, C. H. (2014). A performance-based approach to project assignment and performance evaluation. International Journal of Project Management, 32(2), 218-228. https://doi.org/10.1016/j.ijproman.2013.04.006.

The article has been reviewed.

Received in March 2018; accepted in April 2019. 